\title{
Development of specific materials for the high power electronic components in electric vehicles
}

\author{
Abderrahmen Kaabi ${ }^{1}$, Yves Bienvenu ${ }^{1}$, Bertrand Pierre ${ }^{2}$ and Laurent Prevond ${ }^{3}$ \\ ${ }^{1}$ MinesParisTech, France \\ ${ }^{2}$ GRISET S.A., France \\ ${ }^{3}$ CNAM-SATIE, France
}

\begin{abstract}
The powerchain in electric vehicles sets new demands on semi conductors and their packaging. The latter will be specifically addressed. The power density per $\mathrm{cm} 2$ in DC/DC or DC/AC converters requires a mastering of thermomecahnical aspects. The temperature cyling, the environment under the hood of the vehicles and the "hybrid" technology impose severe constraints on the assemblies which may be met by architectured substrates, new options for assemblies and efficient cooling systems. An optimised semi conductor substrate associating copper and invar in a will be developed, relying on roll bonding to produce the 3D architecture. Roll bonding may also be used to associate aluminium and iron to produce light laminates with a CEM performance.
\end{abstract}

\section{INTRODUCTION}

The heart of the electric vehicles power chain relies on a few $\mathrm{cm}^{2}$ of semiconductor (about $100 \mu \mathrm{m}$ thick) assembled on a metallic substrate in DC/DC and DC/AC power converters. To save space, weight and reduce thermal losses, frequencies are increasing up to $1 \mathrm{MHz}$. Voltages reach close to $1000 \mathrm{~V}$ and power $100 \mathrm{~kW}$ for a mid-size car, which pushes the silicon technology to its limits and cause an interest in wide band gap semi conductors, $\mathrm{SiC}$ or $\mathrm{GaN}$ on $\mathrm{Si}$. The temperature cycles are taking the semi conductor/metal assemblies through variations reaching $200^{\circ} \mathrm{C}$ with temperature differences reaching $100^{\circ} \mathrm{C}$. cooling technologies rely on air cooling and on conduction cooling thanks to a "radiator" and to the connecting wires. In addition to thermomechanical fatigue of the assemblies, Electromagnetic Compatibility (E.M.C) at both high and low frequencies is a concern. Solutions relying on roll bonding to associate a metal with a high thermal conductivity ( $\mathrm{Cu}$ or $\mathrm{Al})$ and one with a low value of the coefficient of thermal expansion, like Invar (or Mo) or with a ferromagnetic character for EMC like iron are considered in the laboratory and are reaching the stage of transfer to industry.

\section{SEMICONDUCTOR/SUBSTRATE ASSEMBLY}

Electric vehicles contain up to 8 pairs of transistors (IGBT type) and diode; hybrid vehicles may contain more, with a lower power level since the thermal engine makes use also of high power electronics ("stop and start" $($ )). The silicon or the alternative semi conductors are low CTE (of the order of $5 \mathrm{ppm} / \mathrm{K}$ ) materials while the copper of the usual substrates is a high CTE $(18 \mathrm{ppm} / \mathrm{K})$ which is the source of thermomecahnical fatigue problems. Solutions to reduce the CTE mismatch rely on copper composites including carbon fibres or even diamonds. Aluminium/ $\mathrm{SiC}$ particles composites are used as substrate in electric locomotives. The solution for the assembly is usually a thin $(<200 \mu \mathrm{m})$ tin based or lead based solder to resist temperature levels of the order of $150^{\circ} \mathrm{C}$. The solders have CTE values in excess of $20 \mathrm{ppm} / \mathrm{K}$.

Thermomechanical damage materializes by cracks at the solder/Si interface. Materials solutions are sought not only at the substrate level but also at the solder level with low CTE composite solders or a replacement by a micro or nano silver paste joined by solid state pressing at temperatures $<300^{\circ} \mathrm{C}$ or by the development of direct silicon/copper bonding using SPS pressing for instance.

The solution presented here rests on an optimization at the level of the substrate between thermal (and electrical) conductivity and CTE. Roll bonding is already proposed on a commercial basis with copper/molybdenum or tungsten or alloy with $\mathrm{Cu} / \mathrm{Cu}$ laminate which is a good solution to reduce the CTE but offers a limited transverse thermal conductivity. A percolation of the copper component from the top to the bottom laminate is needed to restore that conductivity, which, according to our solution is provided by a thermal bridge in copper filling cavities in the central low CTE layer.

The design of the architectured substrate is optimised using a FEM model of the temperature field in the non isothermal assembly. A maximum temperature of $175^{\circ} \mathrm{C}$ imposed at the front face of the silicon die and a flux at the interface with the substrate is imposed by the thermal losses. Parameters are respective thicknesses of the three layers and the fraction of thermal bridges in the central layer.

Following a literature survey, the roll bonding process itself was optimised in a series of experiments using an experimental rolling mill (200 $\mathrm{mm}$ diameter rolls), equipped with a speed control and instrumented for force and exit temperature. Prior to bonding it is necessary to refresh the surfaces by a vigorous brushing and it is recommended to anneal the assemblies after bonding. Under optimised operating conditions the filling o the holes in the Invar laminates by the copper laminate (by plastic deformation) is complete. After a stress relief annealing limited to $450{ }^{\circ} \mathrm{C}$, no reaction is evidenced 


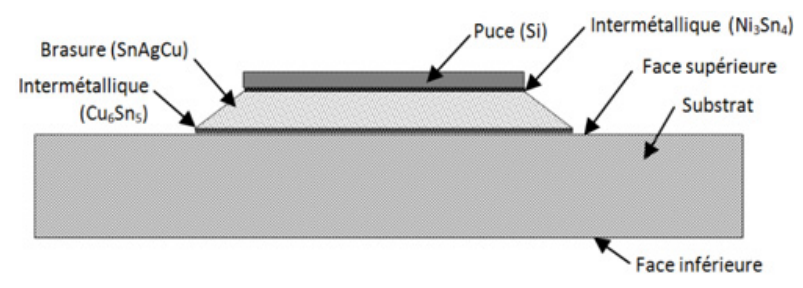

Figure 1. Usual semiconductor/substrate assembly relying on a solder.

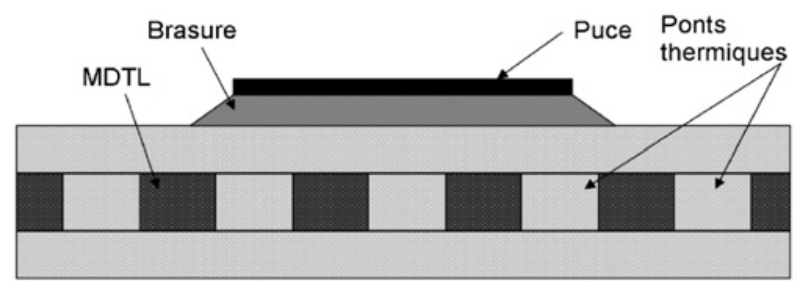

Figure 2. Proposed semiconductor/3D architectured copper substrate assembly. MDTL is a low thermal expansion metal, invar, Fe36Ni, typically.

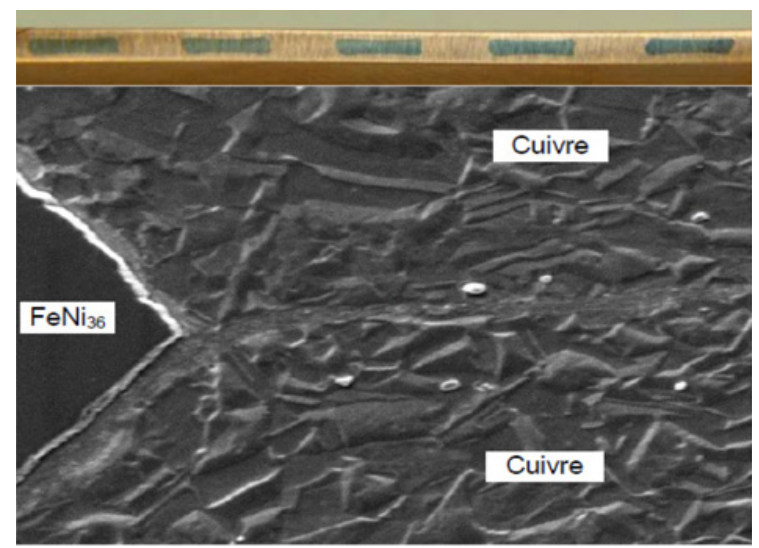

Figure 3. Cross sections of $3 \mathrm{D}$ architectured $\mathrm{Cu} / \mathrm{invar} / \mathrm{Cu}$ roll bonded assembly (Optical microscopy top and S.E.M. bottom) after a deep etch showing perfect filling of the copper bridges and bonds between the metals.

between the two metals and the interdiffusion is limited to a few $\mu \mathrm{m}$.

Measured thermophysical properties are up to expectations from the models and a compromise between CTE and thermal conductivity as good as $10 \mathrm{ppm} / \mathrm{K}$ and $300 \mathrm{~W} / \mathrm{m} . \mathrm{K}$ can be obtained.

\section{ALUMINIUM/IRON/ALUMINIUM ARCHITECTURED ASSEMBLY}

The procedure followed is similar to the one presented above with modelling (of the electromagnetic shielding) and an experimental study of roll bonding. The proportion of iron (or nichel or ferritic steel) is reduced to $10 \mathrm{vol} \%$. Expanded iron or perforated iron foils were used for the central layer.

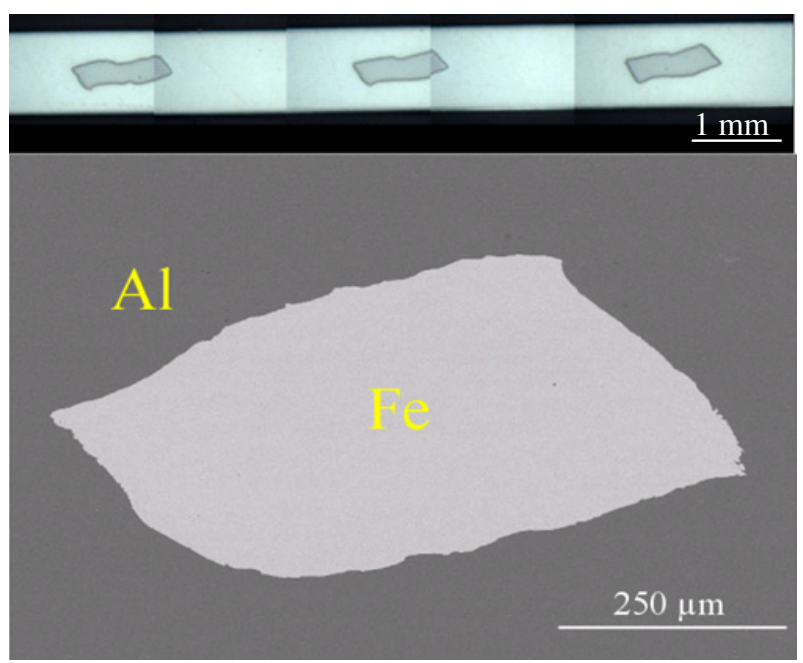

Figure 4. Cross sections of $3 \mathrm{D}$ architectured $\mathrm{Al} / \mathrm{Fe} / \mathrm{Al}$ roll bonded assembly (Optical microscopy top and S.E.M. bottom).

Table 1. E.M. field attenuation when interposing a sheet between emitter and receptor bobbin in a $10^{4}-10^{7} \mathrm{~Hz}$ frequency range.

\begin{tabular}{|l|c|c|c|c|}
\hline & \multicolumn{4}{|c|}{ Frequency (Hz) } \\
\hline $\begin{array}{l}\text { Bi-metal } \\
\text { Thickness }\end{array}$ & $10^{4}$ & $10^{5}$ & $10^{6}$ & $10^{7}$ \\
\hline $\begin{array}{l}\mathrm{Al} / \mathrm{Fe} / \mathrm{Al} \\
1.3 \mathrm{~mm}\end{array}$ & $1.410^{-4}$ & $610^{-6}$ & $510^{-6}$ & $10^{-5}$ \\
\hline $\mathrm{Al}$ & $210^{-4}$ & $10^{-5}$ & $1.110^{-5}$ & $1.110^{-5}$ \\
$1.6 \mathrm{~mm}$ & & & & \\
\hline $\begin{array}{l}\mathrm{Al} / \mathrm{Ni} / \mathrm{Al} \\
0.28 \mathrm{~mm}\end{array}$ & $210^{-4}$ & $10^{-4}$ & $610^{-6}$ & $210^{-7}$ \\
\hline
\end{tabular}

Compared with the previous case, the issue of oxidation of iron during the annealing prior to bonding was important

Strength was assessed by tensile tests and also by 4 point bending tests. Mechanical reinforcement was observed compared to aluminium, et the level or above the rule of mixtures expectations. Annealing of the roll bonded assemblies improve the eleastic modulus by promoting some "chemical bonding" without the formation of detrimental intermetallics.

At low frequencies (below $100 \mathrm{~Hz}$ ) for a given foil thickness, the 3D architecture roll bonded assembly outperforms copper in attenuation.

\section{CONCLUSION}

Roll bonding can do more than producing plain assemblies of three foils, it ca $n$ produce a 3D architecture in which top and bottom layer percolate through holes in the central layer filled during roll bonding by plastic deformation. Those metallic composites offer a satisfactory compromise of properties and the processing cost is limited by the productivity of roll bonding. Applications are proposed for the components specific to the electric vehicles.

ANR and Move'o fro their support and the partners in the Menkar and Aluarmé projects. 